\title{
Effect of Gas-Liquid Ratio on the Membrane Flux in Activated Sludge Process
}

\author{
Shigeki Sawada ${ }^{1)}$, Kazuo Suzuki ${ }^{1)}$, Kunihiro Iwasaki ${ }^{1 \nmid}$ and Kanji Matsumoto ${ }^{2)}$
}

1) Research \& Development Center, Kurita Water Industries, Ltd., 7-1, Wakamiya, Morinosato, Atsugi, Kanagawa 243-0124, Japan

2) Department of Chemical Engineering, Yokohama National University, 79-5, Tokiwadai , Hodogaya, Yokohama Kanagawa 240-8501, Japan

The use of membrane bioreactors (MBRs) is rapidly increasing in the field of organic wastewater treatment. In typical MBR applications for activated sludge processes, the aeration for oxygen supply is also used to maintain high cross-flow liquid velocity over the submerged membrane system (SMS). The prime objective of this study was to demonstrate the effect of presence of gas phase fraction in suspension on the performance of membrane filtration. Experimental studies were performed using two different membrane modules of (1) flat sheet membrane cell (FMC) operated outside the feed tank, where the cross flow velocity of liquid and the volume fraction of gas were changed independently, and (2) flat sheet SMS operated in tank. The relationship between the cross flow velocity, volume fraction of gas phase and the trans-membrane pressure ( TMP ) were determined. It was observed that the rate of increase in TMP did not depend on the presence of gas phase, but depended on the real cross-flow liquid velocity, $\boldsymbol{u}_{\boldsymbol{L}}{ }^{\prime}$, for both the FMC with and without gas phase and the flat-sheet SMS.

Key words: membrane bio-reactor / submerged membrane / air-lift action / gas-liquid two phase flow

\section{Introduction}

Solid-liquid separation is a key step in biological wastewater treatment systems. In typical activated sludge treatment plants a significant variation in sludge settling characteristics is often observed. Poor settling sludge cannot be separated well and normally results in deteriorated plant performance. In membrane bioreactors ( MBRs ) the solid-liquid separation can be achieved independent of settling characteristics of activated sludge and thus the use of membranes for solid-liquid separation is getting popular. Improved solid-liquid separation through membrane separation leads to retention of higher MLSS concentration in the reactor even with sludge of poor settling characteristics.

An activated sludge system with an outside pressurized membrane module operated in a crossflow mode was developed in the United States in the late 1960 's ${ }^{1}$. Subsequently, in the late 1980 's activated sludge systems with cross-flow membrane filtration systems were applied to the treatment of human excreta in Japan to attain high and efficient BOD and nitrogen removal ${ }^{2,3)}$. In these systems with membrane separation, the MLSS concentration in the range of 10,000-15,000 mg/L could be easily achieved using either a plate \& frame type or a tubular type ultrafiltration (UF) module. It was reported that even for such highly concentrated and viscous solid suspension, a filtration flux of $1.0-2.0 \mathrm{~m} / \mathrm{d}$ could be achieved by maintaining cross-flow velocity of 1.5-2.5 $\mathrm{m} / \mathrm{s}$ across the membrane surface ${ }^{2,3}$.

In the late 1980 's, a submerged membrane system (SMS) was developed in which the membrane 
filtration units operate directly in the bioreactor $\tan \mathrm{k}^{4)}$. Recently, various types of SMSs are used to treat organic wastewater. In SMS, air is introduced in the liquid through air diffusers and the introduced air leads to liquid circulation in the reactor. The air induced liquid circulation provides a cross-flow over the submerged membrane surface ${ }^{5,6)}$. An external suction pump is used to create the driving force required for the membrane filtration.

In a submerged membrane system, in addition to the positive effect of cross flow liquid velocity, gas phase flow also can be considered to suppress concentration polarization ${ }^{7}$. Imasaka reported that the steady-state flux in a suction filtration system for bacterium separation from methane fermentation broth using a tubular ceramic membrane was dependent on the sum of superficial gas and liquid velocity in an upward airlift flow ${ }^{8}$. Although in their study mentioned above an upward liquid flow achieved by air-lift action was considered to suppress the membrane fouling, it was not clarified which velocity of air bubble or liquid contributed in suppressing the membrane fouling. Also, the cross-flow liquid velocity depended on the intensity of bubble aeration and due to this interrelationship the individual effects of each phase were difficult to estimate separately. Matsumoto et al. ${ }^{9)}$ reported that the bubbling operation was not so effective in maintaining a high flux in a dense cell broth in a two phase gas-liquid flow system with outside-in capillary membranes for the filtration of lactic acid fermentation broth. Considering the positive effect of air - flow suggested by Imasaka ${ }^{8)}$, the negative results of Matsumoto et. al. ${ }^{9)}$ may be due to very high MLSS concentration in their study. Based on these studies, more study is needed to clarify the relationship between liquid velocity, gas phase fraction and MLSS concentration on the performance of membrane filtration system.

To study the effect of gas phase on membrane filtration performance, it is necessary to vary the liquid velocity and the gas phase fraction arbitrarily.
Top view of submerged flat sheet membrane stack
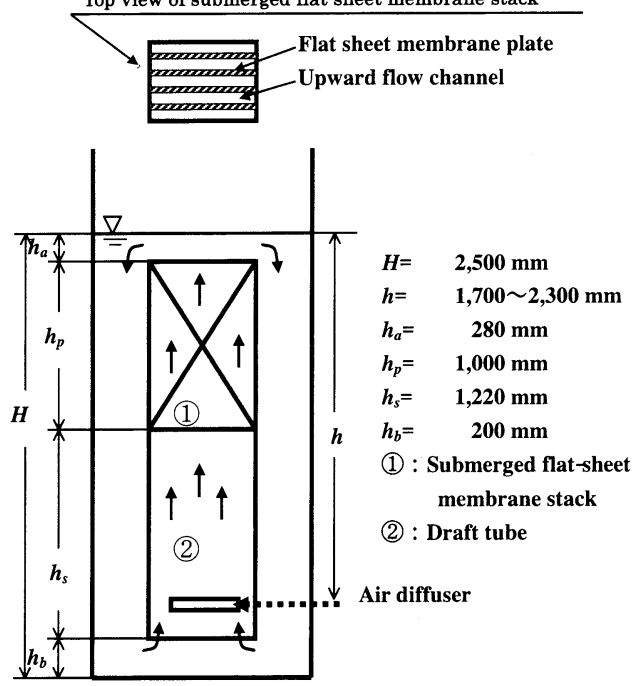

Fig. 1 Schematic diagram of pilot scale submerged membrane tank

However, the liquid circulation without diffused aeration is difficult in a pilot scale SMS. It is necessary to use a large-scale mixer in stead of aeration. This problem can be solved by using a laboratory scale flat-sheet membrane cell ( FMC) in which either single phase liquid flow or two phase gas-liquid flow can be easily achieved.

In this paper experimental studies were performed using both SMS and FMC (with and without air bubbles) by analyzing the rate of increase in transmembrane pressure (TMP) in order to clarify the effect of presence of air bubbles in preventing membrane fouling in a SMS.

\section{Materials and Methods}

\subsection{Submerged Flat-sheet Membrane (SMS) Apparatus}

The pilot scale reactor configuration including the installation details of submerged membrane in a SMS reactor is shown in Fig.1, which is used for treating human excreta. A rectangular draft tube was placed in the center of tank. An air diffuser (nozzle diameter 9 $\mathrm{mm}$ ) was used for aeration and the depth of diffuser 
Table 1 Experimental conditions of bubbling aeration in a flat-sheet SMS

\begin{tabular}{|ll|c|c|c|}
\hline & & Run 1 & Run 2 & Run 3 \\
\hline Flux & \multicolumn{3}{|c|}{0.5} \\
\hline Channel spacing & {$[\mathrm{m} / \mathrm{d}]$} & 13.0 \\
\hline $\boldsymbol{u}_{G}$ & {$[\mathrm{~m} / \mathrm{s}]$} & 0.017 & 0.043 & 0.06 \\
\hline $\boldsymbol{u}_{L}$ in pure water $[\mathrm{m} / \mathrm{s}]$ & 0.44 & 0.65 & 0.75 \\
\hline $\boldsymbol{u}_{L}$ in mixed liquor $[\mathrm{m} / \mathrm{s}]$ & 0.28 & 0.41 & 0.47 \\
\hline Gas hold up $\varepsilon \quad[-]$ & 0.035 & 0.07 & 0.090 \\
\hline $\boldsymbol{u}_{L} \quad[\mathrm{~m} / \mathrm{s}]$ & 0.30 & 0.45 & 0.53 \\
\hline
\end{tabular}

Table 2 Characteristics of the activated sludge mixed liquor

\begin{tabular}{|l|c|}
\hline MLSS $\quad[\mathrm{mg} / \mathrm{L}]$ & $16,000 \sim 20,000$ \\
\hline Soluble COD & $320 \sim 440$ \\
\hline MLSS $[\mathrm{mg} / \mathrm{L}]$ & $1,800 \sim 3,200$ \\
\hline
\end{tabular}

was changed according to experimental requirements. Within the draft tube, membrane plates of $8 \mathrm{~mm}$ thickness, $500 \mathrm{~mm}$ width and $1,000 \mathrm{~mm}$ length were placed with the open spacing of $13 \mathrm{~mm}$ between membrane plates. The water depth in tank, $\boldsymbol{H}$, was 2,500 $\mathrm{mm}$; the maximum diffuser depth, $\boldsymbol{h}$, was 2,300 $\mathrm{mm}$; and the section area ratio $\left(\boldsymbol{S}_{u} / \boldsymbol{S}_{d}\right)$ (where $\boldsymbol{S}_{u}$ is the riser area and $\boldsymbol{S}_{\boldsymbol{d}}$ is the downcomer area) was 0.146 . When the membrane plates were installed in the draft tube, the section area ratio $\boldsymbol{S}_{p} / \boldsymbol{S}_{d}$ (where $\boldsymbol{S}_{p}$ is the effective riser section area) was 0.098 .

Flat-sheet polyolefin MF membrane (Yuasa Corporation) having a pore size of $0.4 \mu \mathrm{m}$ was used in this study. The MF membrane was attached on both sides of the plate with stripe gaps for collecting permeate water. The intermittent suction filtration mode ( 8 minutes on -2 minutes off) was set so as to achieve a constant filtration flux of $0.5 \mathrm{~m} / \mathrm{d}$. The TMP was determined in a two-phase gas-liquid flow mode at different aeration intensities. The conditions of bubble aeration are shown in Table 1 . The airflow rates in the reactor used here were selected so as to achieve gas hold up in the range of $3.5-9.0 \%$. At these conditions the upward liquid velocity was measured at $0.30-0.53 \mathrm{~m} / \mathrm{s}$.

The activated sludge mixed liquor from full-scale plant was supplied to a feed tank equipped with an overflow. The characteristics of activated sludge

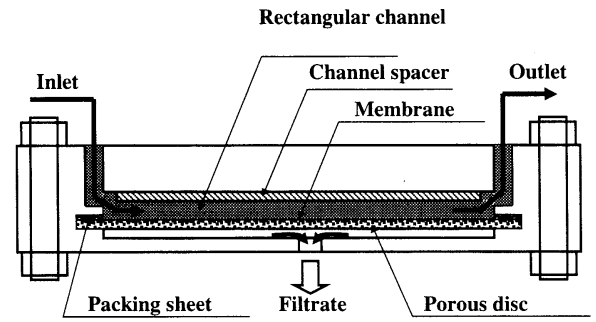

Fig. 2 Cross-sectional view of the flat-sheet membrane test cell ( FMC)

mixed liquor are shown in Table 2. The MLSS concentration varied from $16,000-20,000 \mathrm{mg} / \mathrm{L}$.

\subsection{Measurement of Upward Liquid Velocity in SMS}

The liquid velocity in the pilot scale reactor was measured using a three-dimensional electromagnetic speed flow meter (ALLEC Electron Co.). The probe was placed in the center of downcomer zone to minimize the influence of air bubbles. Since no difference of downward velocity was recognized at each part of the downcomer, the downward liquid velocity, $\boldsymbol{u}_{D}$, in the center of downcomer was used as a representative value. Based on the section area ratio, the upward liquid velocity, $\boldsymbol{u}_{L o}\left(=\boldsymbol{u}_{D} /\left(\boldsymbol{S}_{u} / \boldsymbol{S}_{\boldsymbol{d}}\right)\right)$ without membrane plates and $\boldsymbol{u}_{L}\left(=\boldsymbol{u}_{D} /\left(\boldsymbol{S}_{p} / \boldsymbol{S}_{d}\right)\right)$ with membrane plates inside the draft tube were calculated from the average measured downward velocity in the downcomer.

\subsection{Flat-sheet Membrane Test Cell (FMC) Apparatus}

Fig.2 shows the cross-section view of the laboratory scale transparent acrylic rectangular flow channel cell for flat-sheet membrane with an effective channel width and height of $40 \mathrm{~mm}$ and $460 \mathrm{~mm}$, respectively ${ }^{10}$. In this Flat-Sheet Membrane cell (FMC), the feed channel height was set at $4.4 \mathrm{~mm}$ and $13.4 \mathrm{~mm}$. The feed channel height of $13.4 \mathrm{~mm}$ was similar to the spacing of flat-sheet pilot scale SMS to simulate the flow conditions similar to that in pilot scale reactor. On the other hand, at low channel height of $4.4 \mathrm{~mm}$ it was used to achieve high cross-flow velocities above $0.5 \mathrm{~m} / \mathrm{s}$. 


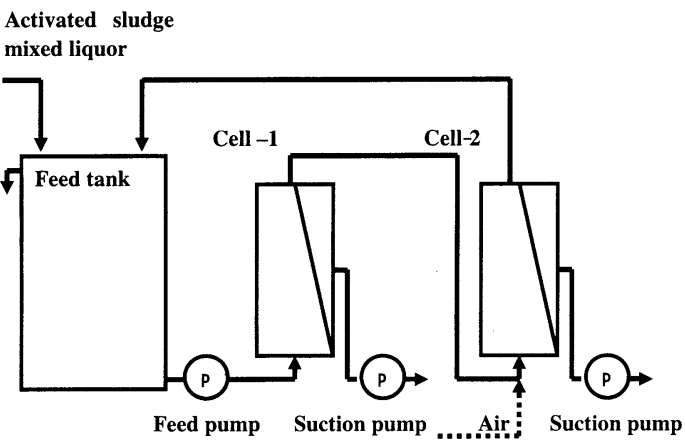

Fig. 3 Schematic diagram using FMCs with and without air bubbling

Authors $^{11)}$ demonstrated that the difference in steady state flux for channel heights of 4.4 and $13.4 \mathrm{~mm}$ was at most $20 \%$ by using a similar configuration of FMC for cross-flow membrane filtration of activated sludge in their previous study in which MLSS concentration was set at $7,000-22,000 \mathrm{mg} / \mathrm{L}$ and cross-flow velocity was set at $1.0-2.5 \mathrm{~m} / \mathrm{s}$. Though there existed some difference between them, the influence of channel heights on the rate of increase in TMP was neglected in data interpretation.

To simultaneously determine the differences in performance between single-phase liquid flow and two-phase gas-liquid flow, two cells were coupled horizontally in series, as is shown in Fig.3. The activated sludge mixed liquor in a single liquid phase was fed to the cross-flow cell-1 by feed pump (Monod type). Compressed air was injected to the feed line just upstream of cell-2 to provide two phase gas-liquid flow. The experimental conditions for tests using FMCs are shown in Table 3. The gas hold up was calculated by the relationship between the superficial gas velocity and the superficial liquid velocity. The gas hold up in our experiment varied in a rage of $10-$ $40 \%$. The peristaltic pumps were used for suction. The feed pump operated continuously while the suction pump operated intermittently with a cycle of 8 minutes on and 2 minutes off. The TMP was measured from the difference between the feed water pressure in the cell and the pressure on the filtrate side. The same 0.4
Table 3 Experimental conditions of a flat-sheet membrane test cell- 1 and cell- 2

\begin{tabular}{|ll|c|c|c|c|c|c|}
\hline & & \multicolumn{3}{|c|}{ Cell-1 } & \multicolumn{3}{c|}{ Cell-2 } \\
\hline Flux & {$[\mathrm{m} / \mathrm{d}]$} & \multicolumn{3}{|c|}{0.5} & \multicolumn{3}{c|}{0.5} \\
\hline Channel height & {$[\mathrm{mm}]$} & 13.4 & 4.4 & 4.4 & 13.4 & 13.4 & 4.4 \\
\hline $\boldsymbol{u}_{\boldsymbol{L}}+\boldsymbol{u}_{\boldsymbol{G}}$ & {$[\mathrm{m} / \mathrm{s}]$} & 0.30 & 0.50 & 0.70 & 0.28 & 0.47 & 0.68 \\
\hline $\boldsymbol{u}_{\boldsymbol{L}}$ & {$[\mathrm{m} / \mathrm{s}]$} & 0.30 & 0.50 & 0.70 & 0.25 & 0.40 & 0.5 \\
\hline $\boldsymbol{u}_{G}$ & {$[\mathrm{~m} / \mathrm{s}]$} & 0 & 0 & 0 & 0.03 & 0.17 & 0.18 \\
\hline Gas hold up $\varepsilon$ & {$[-]$} & 0 & 0 & 0 & 0.11 & 0.36 & 0.26 \\
\hline
\end{tabular}

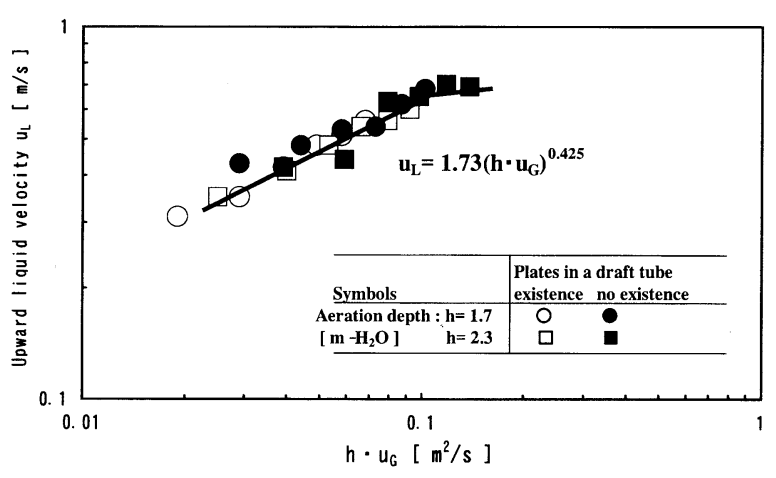

Fig. 4 Relationship between $\boldsymbol{u}_{G} \cdot \boldsymbol{h}$ and $\boldsymbol{u}_{L}$ in a draft tube with and without flat-sheet membrane plates

$\mu \mathrm{m}$ MF membrane as used for the pilot scale flatsheet SMS apparatus was used in these experiments.

The MLSS concentration during these experiments varied from $16,000-18,000 \mathrm{mg} / \mathrm{L}$ that were similar to the experiment in a SMS.

\section{Results and Discussion}

\subsection{Upward Liquid Velocity}

In order to determine the cross-flow velocity caused by the air-lift action in a draft tube and the effect of MLSS concentration on the cross-flow velocity, upward liquid velocity, $\boldsymbol{u}_{L}$, was measured with the tap water and the activated sludge mixed liquor. At first the tap water was used to determine a relationship between $\boldsymbol{u}_{L}$, and $\boldsymbol{h} \cdot \boldsymbol{u}_{G}$ (refer to Appendix A). Two test runs 1 ) with and 2) without membrane plates in the draft tubes were performed. The data is collectively plotted in Fig. 4 for both runs. The relationship between $\boldsymbol{u}_{L}$ and $\boldsymbol{h} \cdot \boldsymbol{u}_{G}$ was found to be similar for both runs. The following empirical equation was obtained for $\boldsymbol{h} \cdot \boldsymbol{u}_{G}$ values ranging 


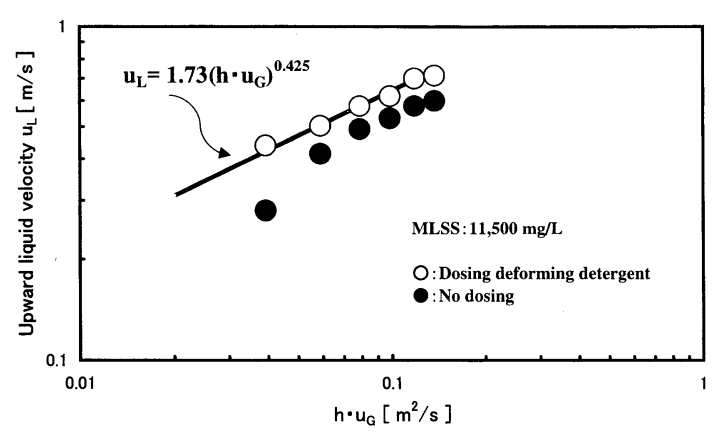

Fig. 5 Relationship between $\boldsymbol{u}_{G} \cdot \boldsymbol{h}$ and $\boldsymbol{u}_{L}$ in an activated sludge mixed liquor

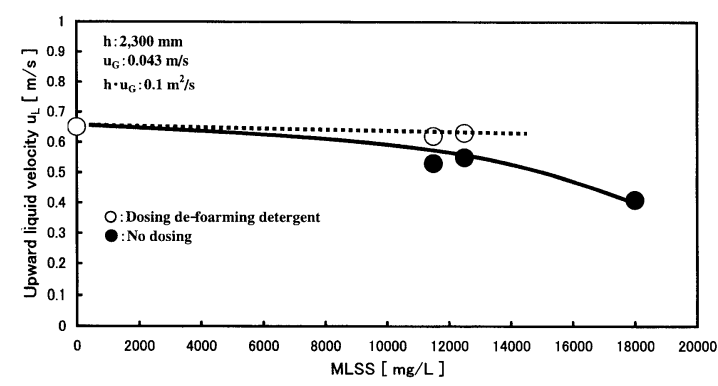

Fig. 6 Relationship between MLSS and up ward liquid velocity $\boldsymbol{u}_{\boldsymbol{L}}$

between $0.01-0.1 \mathrm{~m}^{2} / \mathrm{s}$.

$$
\boldsymbol{u}_{L}=\boldsymbol{u}_{\boldsymbol{L}}{ }^{\prime} \times(1-\boldsymbol{\varepsilon})=1.73 \times\left(\boldsymbol{h} \cdot \boldsymbol{u}_{G}\right)^{0.425}
$$

When the value of $\boldsymbol{h} \cdot \boldsymbol{u}_{G}$ was increased to more than $0.1 \mathrm{~m}^{2} / \mathrm{s}$, the liquid velocity did not increase any more. This would be due to the reduction of density difference of liquid in the riser and downcomer by the entrapment of a larger amount of air bubbles in the downcomer at higher liquid velocity in downcomer.

For activated sludge mixed liquor, $\boldsymbol{u}_{L}$ was measured by setting the air diffuser depth, $\boldsymbol{h}$, at $2,300 \mathrm{~mm}$. At these conditions, the activated sludge mixed liquor foamed intensively. Therefore, a de-foaming detergent was added to the reactor to measure the upward liquid velocity under non-foaming condition. Fig. 5 shows the relationship between $\boldsymbol{u}_{\boldsymbol{L}}$ and $\boldsymbol{h} \cdot \boldsymbol{u}_{G}$ in the activated sludge mixed liquor with and without the addition of de-foaming detergent. The relationship between $\boldsymbol{u}_{L}$ and $\boldsymbol{h} \cdot \boldsymbol{u}_{G}$ in the activated sludge mixed liquor with

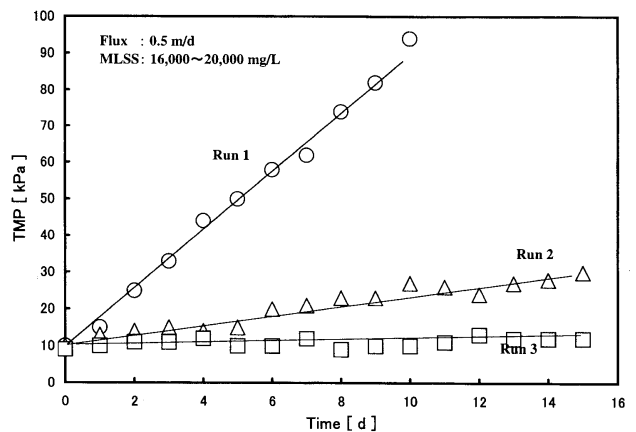

Fig. 7 Relationship between filtration time and TMP in a SMS

and without the addition of de-foaming detergent was found to be similar to that observed for tap water. Fig.6 shows the relationship between MLSS concentration and $\boldsymbol{u}_{L}$ by setting $\boldsymbol{u}_{G}$ (superficial gas flow velocity) at $0.043 \mathrm{~m} / \mathrm{s}$ (where $\boldsymbol{h} \cdot \boldsymbol{u}_{\boldsymbol{G}}$ was $0.1 \mathrm{~m}^{2} / \mathrm{s}$ ). When a de-foaming detergent was not added at the condition of high MLSS concentration, $\boldsymbol{u}_{L}$ decreased with increasing MLSS concentration. At MLSS concentration of $18,000 \mathrm{mg} / \mathrm{L}$ without a de-foaming detergent, $\boldsymbol{u}_{L}$ was $63 \%$ when compared to that observed for tap water. The foaming at high MLSS concentration negatively affects the degassing causing a reduced density difference of sludge in the riser and downcomer which in effect leads to lower liquid velocities.

In order to maintain high cross-flow velocity in SMS, a de-foaming detergent is requested to be added at high MLSS concentration. However a de-foaming detergent is not applicable for MBR because of accelerating membrane fouling. Therefore, the value of upward liquid velocity at the MLSS concentration ranging between $16,000-20,000 \mathrm{mg} / \mathrm{L}$ is limited at the ranging between $0.4-0.6 \mathrm{~m} / \mathrm{s}$ when a de-foaming detergent is not used.

\subsection{Two Phase Gas-Liquid Cross-Flow Filtration in the Flat-sheet SMS}

In the flat-sheet SMS the relationship between the real upward cross-flow liquid velocity, $\boldsymbol{u}_{L}{ }^{\prime}$, and the rate of increase in TMP was determined. Since the 


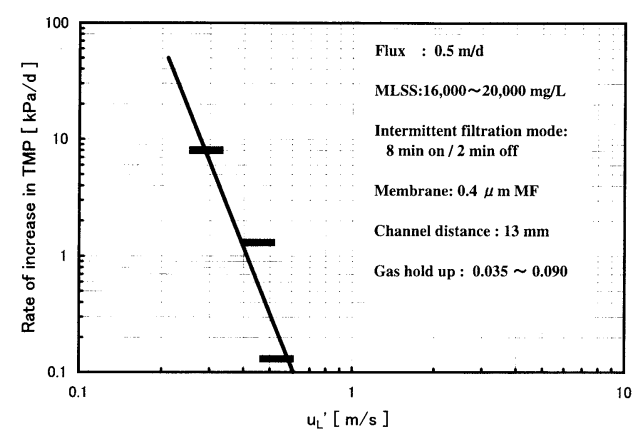

Fig. 8 Relationship between the real upward cross-flow liquid velocity, $\boldsymbol{u}_{L}{ }^{\prime}$, in a flat-sheet SMS and the rate of increase in TMP

TMP increases linearly in a constant flow filtration if the cake layer is formed constantly (refer to Appendix B), the rate of increase in TMP in the SMS was determined from the slope of the straight line of TMP vs. filtration time, which is shown in Fig.7. The $\boldsymbol{u}_{L}$ in the riser between membrane plates was calculated based on the estimated value for the concentration of MLSS at $18,000 \mathrm{mg} / \mathrm{L}$ presented in Fig.4 and 6. The value of $\boldsymbol{u}_{L}^{\prime}\left(=\boldsymbol{u}_{L} /(1-\varepsilon)\right)$ was calculated based on equations (A - 5 and A -6 in Appendix A ) with the value of slip velocity, $\boldsymbol{u}_{s}=0.2 \mathrm{~m} / \mathrm{s}$, obtained from the measurement of upward air bubble velocity in a column test.

The relationship between the rate of increase in TMP and $\boldsymbol{u}_{L}{ }^{\prime}$ is shown in Fig.8. The rate of increase in TMP was dependent on $\boldsymbol{u}_{L}{ }^{\prime}$ and the following empirical equation was obtained.

The rate of increase in TMP $=5.67 \times 10^{-3} \times\left(\boldsymbol{u}_{L}{ }^{\prime}\right)^{-6.0}(2)$

Eq. (2) is a useful expression for deciding the operational condition in SMS. For example, supposing that $30 \mathrm{kPa}$ in TMP at which chemical cleaning is applied and that the cleaning interval is set for 100 days, the permissible value of the rate of increase in TMP is calculated to be $0.3 \mathrm{kPa} / \mathrm{d}$. In order to maintain the permissible rate of increase in TMP, the operational $\boldsymbol{u}_{L}{ }^{\prime}$ can be estimated from Eq. (2) to be at more than $0.4 \mathrm{~m} / \mathrm{s}$.

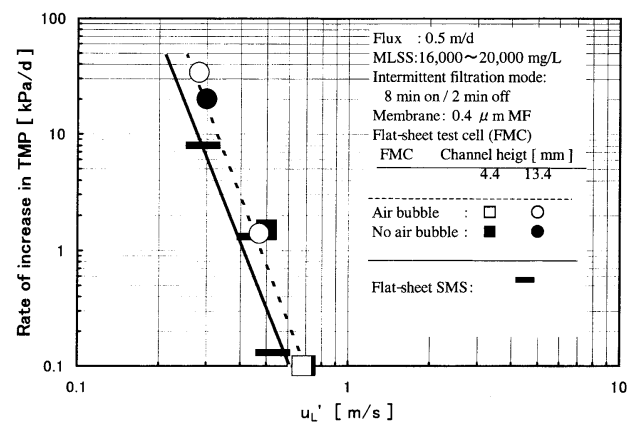

Fig. 9 Comparison between a flat-sheet SMS and a FMC with and without air bubbling in the relationship between $\boldsymbol{u}_{L}{ }^{\prime}$ and the rate of increase in TMP

Since, in the above experiments, $\boldsymbol{u}_{L}{ }^{\prime}$ directly depends on $\boldsymbol{u}_{G}$ as is shown in Eq. (1), an individual significance of each of intensity of bubble aeration and cross-flow liquid velocity in suppressing the rate of increase in TMP can not be clarified. Hence, the relationship between the rate of increase in TMP and the cross-flow liquid velocity with and without air bubbles was investigated by using FMC in which $\boldsymbol{u}_{L}$ and $\boldsymbol{u}_{G}$ can be varied independently.

\subsection{Two Phase Liquid-Gas Cross-Flow Filtration in a Flat-sheet Membrane Cell ( FMC)}

Fig.9 shows the comparative performances of FMC with and without air bubbles together with the results of SMS. For a two phase gas-liquid flow in a FMC, the real cross-flow liquid velocity, $\boldsymbol{u}_{L}{ }^{\prime}$, can be approximated by the following equation:

$$
\boldsymbol{u}_{L}^{\prime}=\boldsymbol{u}_{L}+\boldsymbol{u}_{G}
$$

where $\boldsymbol{u}_{L}=\boldsymbol{Q}_{L} / \boldsymbol{S}_{F}$ and $\boldsymbol{u}_{G}=\boldsymbol{Q}_{G} / \boldsymbol{S}_{F}$. In this experiment, $\boldsymbol{u}_{L}$ and $\boldsymbol{u}_{G}$ were set at the range of $0.3-0.7 \mathrm{~m} / \mathrm{s}$ and $0.03-0.18 \mathrm{~m} / \mathrm{s}$, respectively.

It was demonstrated that the difference in the rate of increase in TMP between two phase gas-liquid flow and single phase liquid flow was small as is shown in Fig.9. The relationship between the real cross-flow liquid velocity and the rate of increase in TMP in FMC was found to be similar to that of two-phase 
liquid-gas flow in a flat-sheet SMS. But the rate of increase in TMP in SMS was a little higher than that in FMC at the same cross-flow liquid velocity. This small difference is due to the difference in configuration, feed pressure value or filtration mode between FMC and SMS. It is concluded from the relationship in Fig.9 that the rate of increasing TMP in a cross-flow filtration is not determined by $\boldsymbol{u}_{L}$ or $\boldsymbol{u}_{G}$, but by the real cross-flow liquid velocity, $\boldsymbol{u}_{L}$ '.

\section{Conclusions}

For design considerations, the relationship between the rate of increase in TMP and the real cross-flow liquid velocity for both, a flat-sheet SMS and a FMC (with and without air bubbles) was investigated. Following conclusions could be drawn from the study. 1) The upward liquid velocity caused by the air-lift action in a draft tube placed within the flat-sheet SMS can be expressed as the power function of the product of aeration depth, $\boldsymbol{h}$, and the superficial gas velocity, $\boldsymbol{u}_{G}$.

2) The rate of increase in TMP in a flat-sheet SMS was dependent on the real upward cross-flow liquid velocity, $\boldsymbol{u}_{L}^{\prime}\left(=\boldsymbol{u}_{L} /(1-\varepsilon)\right)$.

3) The rate of increase in TMP in a FMC using gas rich two phase gas-liquid (gas hold up: $10-40 \%$ ) is dependent on the real cross-flow liquid velocity, $\boldsymbol{u}_{L}$ '. This relationship is in agreement with that observed with single-phase activated sludge flow.

4) The relationship between the rate of increase in TMP and the real upward cross-flow liquid velocity in a flat-sheet SMS is roughly agreed with that in a FMC with and without air bubbles.

\section{Appendix A: Upward velocity driven by air-lift pump}

An air-lift circulation is driven by the density difference in the riser and downcomer. The potential hydrostatic difference, $\Delta \boldsymbol{P}_{S}$, between the riser and downcomer is defined by ${ }^{12)}$

$$
\Delta \boldsymbol{P}_{S}=\varepsilon \cdot \rho_{L} \cdot \boldsymbol{h}
$$

where $\varepsilon$ : gas hold up, $\rho_{L}$ : liquid density, $\boldsymbol{h}$ : aeration depth of water.

Head loss $\Delta \boldsymbol{P}_{f}$ driven by a circulation flow is related by

$$
\Delta \boldsymbol{P}_{f}=f \cdot \rho_{L} \cdot \boldsymbol{u}_{L}^{2} \cdot 1 / 2
$$

where $f$ : friction coefficient, $\boldsymbol{u}_{L}:$ a circulation flow superficial liquid velocity.

Real upward gas velocity, $\boldsymbol{u}_{G}^{\prime}$, and real upward liquid velocity, $\boldsymbol{u}_{L}{ }^{\prime}$, are approximated by the following relationships with gas hold up $\varepsilon$.

$$
\begin{aligned}
& \boldsymbol{u}_{G}{ }^{\prime}=\boldsymbol{u}_{G} / \varepsilon \\
& \boldsymbol{u}_{L}{ }^{\prime}=\boldsymbol{u}_{L} /(1-\varepsilon)
\end{aligned}
$$

where $\boldsymbol{u}_{G}$ : superficial upward gas velocity.

The slip velocity of air bubbles is given by Eqs. (A-3 ) and ( A-4 $)^{12)}$ :

$$
\boldsymbol{u}_{S}=\boldsymbol{u}_{G}{ }^{\prime}-\boldsymbol{u}_{L}{ }^{\prime}=\boldsymbol{u}_{G} / \varepsilon-\boldsymbol{u}_{L} /(1-\varepsilon)
$$

Since gas hold up is several percent and it can be approximated with $(1-\varepsilon) \doteqdot 1.0$ in an air-lift circulation operation, the relation between gas hold up and velocity leads to

$$
\varepsilon=\boldsymbol{u}_{G} /\left(\boldsymbol{u}_{S}+\boldsymbol{u}_{L}\right)
$$

In the steady state, since $\Delta \boldsymbol{P}_{S}=\Delta \boldsymbol{P}_{f}$ can be approximated as follows from Eqs. ( A-1 ), ( A-2 ) and (6-6).

$$
u_{L}^{2}=2 \boldsymbol{h} \cdot \boldsymbol{u}_{G} /\left(f \cdot\left(\boldsymbol{u}_{S}+\boldsymbol{u}_{L}\right)\right)
$$

When a superficial upward liquid velocity, $\boldsymbol{u}_{L}$, is equivalent to a slip velocity, $\boldsymbol{u}_{S}$, or large, $\boldsymbol{u}_{L} \geqq \boldsymbol{u}_{S}$, Eq. ( A-8) leads to

$$
\boldsymbol{u}_{L} \propto\left(\boldsymbol{h} \cdot \boldsymbol{u}_{G}\right)^{1 / 3 \sim 1 / 2}
$$

Eq. ( A-8) is proportional to power of ${ }^{1 / 3-1 / 2}$ of the product of aeration depth, $\boldsymbol{h}$, and superficial upward gas velocity, $\boldsymbol{u}_{G}$.

\section{Appendix B : Rate of increase in TMP}

If the gel layer or cake layer depends on membrane filtration resistance, the relationship between flux and TMP in constant flux filtration can be calculated by Eq. ( B-1 $)^{13)}$ : $\Delta \boldsymbol{P} / \Delta \boldsymbol{P}_{M}=\left(\boldsymbol{R}_{C}+\boldsymbol{R}_{M}\right) / \boldsymbol{R}_{M}$ 


$$
=1+\boldsymbol{a}_{C} \cdot \boldsymbol{C} \cdot \boldsymbol{J} \cdot \boldsymbol{t} / \boldsymbol{R}_{M}
$$

where $\Delta \boldsymbol{P}:$ TMP, $\Delta \boldsymbol{P}_{M}$ : initial TMP, $\boldsymbol{R}_{C}$ : cake resistance, $\boldsymbol{R}_{M}$ : membrane resistance, $\boldsymbol{\alpha}_{C}$ : specific cake resistance, $\boldsymbol{C}$ : concentration of foulant, $\boldsymbol{J}$ : flux and $\boldsymbol{t}$ : filtration time.

If the cake layer shows incompressibility when a filtration pressure is low, and it is $\boldsymbol{R}_{C} \gg \boldsymbol{R}_{M}$, Eq. ( B-1) can be given by

$$
\Delta \boldsymbol{P}=\mu \cdot a_{C} \cdot \boldsymbol{C} \cdot \boldsymbol{J} \cdot \boldsymbol{t}
$$

Therefore, with constant composition of activated sludge and at low pressure, TMP may increase linearly with time.

\section{Nomenclature}

C : concentration of foulant $\left[\mathrm{kg} / \mathrm{m}^{3}\right]$

$\boldsymbol{H}:$ aeration depth of water [ $\mathrm{m}]$

$\boldsymbol{J}$ : flux of permeate [ $\mathrm{m} / \mathrm{s}$ ]

$\Delta \boldsymbol{P}$ : trans-membrane pressure $[\mathrm{kPa}]$

$\Delta \boldsymbol{P}_{M}$ : initial trans-membrane pressure [ $\left.\mathrm{kPa}\right]$

$\Delta \boldsymbol{P}_{f}$ : potential hydrostatic difference [ $\left.\mathrm{kPa}\right]$

$\Delta \boldsymbol{P}_{S}:$ head loss [ $\left.\mathrm{kPa}\right]$

$\boldsymbol{Q}_{\boldsymbol{L}} \quad$ : feed liquid flowrates in FMC $\left[\mathrm{m}^{3} / \mathrm{s}\right]$

$\boldsymbol{Q}_{G} \quad:$ feed gas flowrates in FMC [ $\left.\mathrm{m}^{3} / \mathrm{s}\right]$

$\boldsymbol{R}_{C} \quad$ : cake resistance [ $1 / \mathrm{m}$ ]

$\boldsymbol{R}_{M} \quad:$ membrane hydraulic resistance $[1 / \mathrm{m}$ ]

$\boldsymbol{s}_{u} \quad$ : riser area in tank $\left[\mathrm{m}^{2}\right]$

$\boldsymbol{s}_{\boldsymbol{d}}:$ downcomer area in tank $\left[\mathrm{m}^{2}\right]$

$\boldsymbol{s}_{p}$ : effective riser sectional area with membrane plates installed in draft tube $\left[\mathrm{m}^{2}\right]$

$\boldsymbol{s}_{F}$ : sectional area of feed channel in FMC $\left[\mathrm{m}^{2}\right]$

$\boldsymbol{t}$ : filtration time [ $\mathrm{s}$ ]

$\boldsymbol{u}_{D} \quad$ : superficial downward liquid velocity [ $\mathrm{m} / \mathrm{s}$ ]

$\boldsymbol{u}_{G} \quad$ : superficial upward gas velocity [ $\mathrm{m} / \mathrm{s}$ ]

$\boldsymbol{u}_{L} \quad$ : superficial upward liquid velocity with membrane plates in SMS [ $\mathrm{m} / \mathrm{s}$ ]

$\boldsymbol{u}_{L \theta}$ : superficial upward liquid velocity without membrane plates in SMS [ $\mathrm{m} / \mathrm{s}$ ]

$\boldsymbol{u}_{\boldsymbol{G}^{\prime}} \quad$ : real upward gas velocity $[\mathrm{m} / \mathrm{s}]$

$\boldsymbol{u}_{L}{ }^{\prime} \quad$ : real upward liquid velocity $[\mathrm{m} / \mathrm{s}$ ]

$\boldsymbol{u}_{s} \quad$ : slip velocity of air bubbles $[\mathrm{m} / \mathrm{s}$ ]
$\alpha_{C}:$ specific cake resistance $[\mathrm{m} / \mathrm{kg}$ ]

$\varepsilon$ : gas hold up [ - ]

$\mu:$ viscosity of liquid $[\mathrm{Pa} \cdot \mathrm{s}$ ]

$\rho_{L}:$ liquid density $\left[\mathrm{kg} / \mathrm{m}^{3}\right]$

\section{Reference}

1) Smith CV, Gregorio DD, Talcott, RM: Proceedings of 25th Annual Purdue International Waste Conf., 1300 (1969)

2) Magara, M. and Itoh, M. : Wat. Sci. Tech., 23, 7-8, 1583 (1991)

3) Satoh, T. and Ishii, Y. : Wat. Sci. Tech., 23, 7-8, 1601 (1991)

4) Nakagome, K. : Japanese PAT No.1874881

5) Hiasa, M. , Yamamoto, K. , Matsuo, T. : Proceedings of 25th Annual Meeting of Japan Sewage Works Association, 366 (1988) (in Japanese)

6) Yamamoto, K., Hiasa, M., Mahmood, T., Matsuo, T: Wat. Sci. Tech. ,21, 4-5, 43 (1989)

7) Chang, S and Fane, A.G. : J.Memb. Sci.,184, 221 (2001)

8) Imasaka, T. : Doctoral thesis, The university of Tokyo, Japan, (1989) (in Japanese)

9) Matsumoto, K. Kitabayashi, K., Ohya, H : Hakkokogaku Kaishi, 69, 477 (1991)

10) Sawada, S. and Oinuma, M.: Chemical and engineering, Kagaku Kohgyousha, Tokyo Japan, 36, 584 (1991) (in Japanese)

11) Sawada, S. and Ishii, Y.: kagakukougaku symposium series 41, p.82, The Society of Chemical Engineers Japan, Tokyo(1994) (in Japanese)

12) Hoshino, S. Kubota, H., Kasakura, T., Koyama, T: Gesuidou Kyoukaishi, 14,160, 25 (1977) (in Japanese)

13) Matsumoto, K. : User no tameno jitsuyou makubunnrigijyutsu, p.86, Nikkan Kougyou Shinbunsha, Tokyo (1996) (in Japanese)

（受付 2001年6月27日 修正稿受付 2002年1月15日 揭載決定 2月25日） 